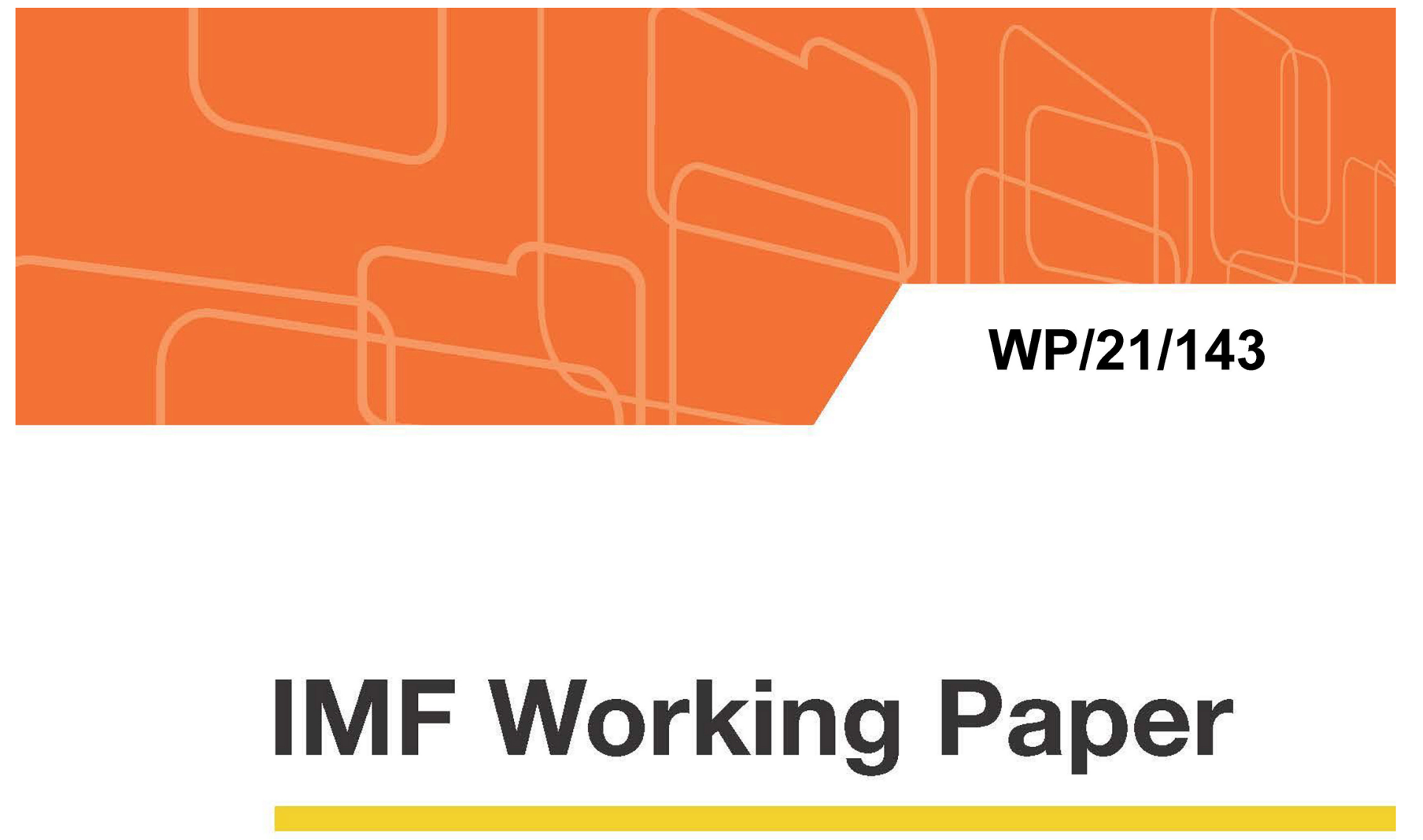

\title{
Scenario Analysis with the DD-PD Mapping Approach: Stock Market Shocks and U.S. Corporate Default Risk
}

\author{
by Jorge A. Chan-Lau
}

IMF Working Papers describe research in progress by the author(s) and are published to elicit comments and to encourage debate. The views expressed in IMF Working Papers are those of the author(s) and do not necessarily represent the views of the IMF, its Executive Board, or IMF management. 


\title{
IMF Working Paper
}

Strategy, Policy and Review Department

\section{Scenario Analysis with the DD-PD Mapping Approach: Stock Market Shocks and U.S. Corporate Default Risk Prepared by Jorge A. Chan-Lau}

Authorized for distribution by Daria Zakharova

May 2021

\section{IMF Working Papers describe research in progress by the author(s) and are published to} elicit comments and to encourage debate. The views expressed in IMF Working Papers are those of the author(s) and do not necessarily represent the views of the IMF, its Executive Board, or IMF management.

\begin{abstract}
This paper introduces the quantile regression- based Distance-to-Default to Probability of Default (DD-PD) mapping, which links individual firms' DD to their real world PD. Since changes in the DD depend on a handful of parameters, the mapping easily accommodates shocks arising from quantitative and narrative scenarios informed by expert judgment. At end-2020, risks from stock market corrections in the U.S. are concentrated in the energy, financial and technology sectors, and additional bank capital needs could be large. The paper concludes discussing uses of the mapping beyond PD valuation suitable for capital structure analysis, credit portfolio management, and long-term scenario planning analysis.
\end{abstract}

JEL Classification Numbers: C22, C53, G32

Keywords: probability of default, distance-to-default, default risk, stock markets, quantile regression, scenario analysis, stress test

Author's E-Mail Address: jchanlau@imf.org

This paper benefitted from comments by Jin-Chuan Duan, Nicola Pierri, and seminar participants at the IMF. Any remaining errors and/or omissions are the author's sole responsibility. 


\section{Contents}

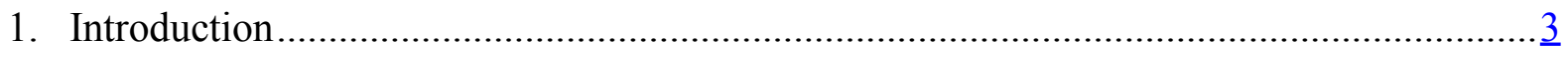

2. Equity Prices and Probability of Default: Anecdotal Evidence..................................... 4

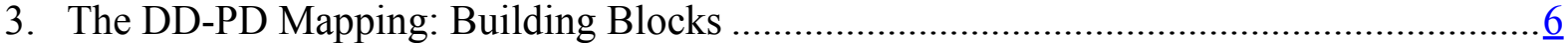

3.1. The Black-Scholes-Merton (BSM) Distance-to-Default (DD) ................................. $\underline{6}$

3.2. Forward Intensity-based Probabilites of Default (CRI-PDs) ..................................

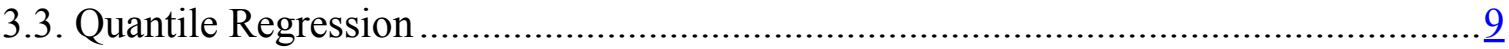

4. Scenario Analysis with the DD-PD Model ..............................................................11

5. Scenario Analysis: Corporate Sector Risk in the United States .................................13

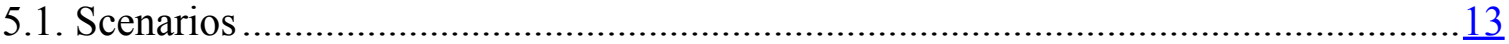

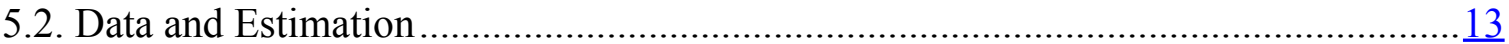

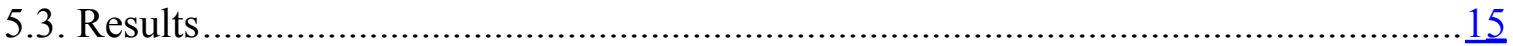

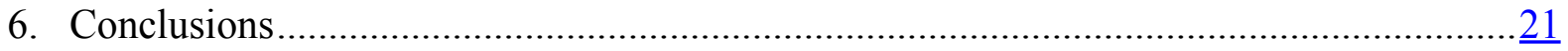

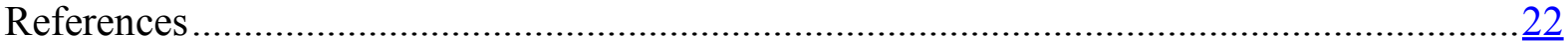




\section{Introduction}

The recurrent occurrence of financial crises following periods of asset overvaluation keeps focusing the attention of academics, market participants, policy makers, and the general public on the seemingly disconnect between asset prices and the economy (Brunnermeier and Oehmke, 2013). At the beginning of the Covid-19 pandemic in 2020 stock markets experienced large price declines. However, by end-2020, markets retraced back their losses to reach historical record high levels. The stock market recovery stood in sharp contrast to the dismal economic fundamentals in most countries, and at the time, high uncertainty about a viable Covid-19 vaccine.

High equity valuations raise questions about the potential mispricing of corporate default risk. High equity prices, however, do not necessarily imply that the probability of default (PD) of a firm is low. The PD depends not only on the market value of the firm but on economy-wide macro financial factors as well as the firm's leverage, profitability and liquidity. ${ }^{1}$ Modeling this relationship is important for analysts interested in examining the impact of stock market shocks, interest rate changes, and changes of a firm's liability structure on corporate default risk.

Examples of models that explicitly incorporate the impact of economic and/or financial scenarios on PDs include, among others, Baldassari et al. (2017), Simons and Rolwes (2018), Tressel and Dao (2020), and Duan et al. (2020). ${ }^{2}$ Applying these models, however, require the specification of multi-period scenarios that account for the joint dynamics of several macro-financial variables. The design and specification of multi-period, multi-variable scenarios is not a trivial task and it may require the joint effort of a sizable modeling team which small institutions cannot afford.

An alternative to multi-period scenario-based models is to estimate a simple empirical relationship, or mapping, between PDs and a suitable market-based risk measure. Ideally, the measure should be economically interpretable and grounded on theory. This paper proposes such a mapping, the Distance-to-Default to PD $(D D-P D)$ mapping. The model builds on the solid foundations provided by the DD measure derived from a benchmark structural model of corporate default risk (Black and Scholes, 1973; Merton, 1974); the high empirical accuracy of firm-level PD estimates generated by a production-quality forward intensity model (Duan, Sun, and Wang, 2012); and the flexibility of quantile regressions (QR; Koenker and Bassett, 1978) to capture the distribution of PDs corresponding to a given value of the DD. ${ }^{3}$

The sections below explain in detail the DD-PD mapping and its application to analyze corporate sector risk in the United States. Section 2 reviews some anecdotal evidence on equity prices and probability of default in the corporate sector. Section 3 describes the three building blocks of the mapping -the structural model, the forward intensity PDs, and the quantile regression. Special attention is focused on the computational details involved in the calculation of the latent parameters of the model, the asset value and its volatility.

As in other quantile regression approaches to model risk, such as the IMF's Growth-at-Risk forecasting model (Adrian et al. 2018) or the CoRisk measure (Chan-Lau, 2009, 2019), each of the QR lines in the DD-PD

\footnotetext{
${ }^{1}$ See Duan, Sun, and Wang (2012) and references therein.

${ }^{2}$ The Duan et al. (2020) model, the Bottom-Up Default Analysis (BuDA) model covers all publicly listed firms in more than 100 countries. The web scenario analyzer can be accessed at the url of the Credit Research Initiative, Asian Institute for Digital Finance, National University of Singapore: https://nuscri.org

${ }^{3}$ The attentive reader would realize that the DD-PD mapping becomes unnecessary if one uses the DSW model directly. The model input, however, comprises sixteen covariates some of which are not easy to calculate or to project under different scenarios (see below). The high modeling skill level involved in using the DSW model in scenario analysis can be assessed from the user's guide of the Bottom-Up Default Analysis (BuDA) calculator CRI (2019a), and some policy applications such as IMF (2016) and Miyajima et al (2017). The DD-PD mapping can be regarded as a simpler alternative to conduct the full-fledged BuDA analysis. Expert judgment, however, is necessary for reducing a full macro-financial scenario to a few parameter changes. But such judgment is not critical if the purpose is to perform simple sensitivity analysis.
} 
mapping can be associated with a different risk regime: high quantile lines correspond to high risk regimes and vice-versa. Section 4 explains how to exploit this interpretation of the QR lines in scenario analysis, especially for establishing a baseline risk regime and perform stress tests.

Section 5 focuses on applications. It uses the mapping to evaluate the impact of three scenarios on the default risk in the U.S. corporate sector. For simplicity the analysis is presented at the sectoral level rather than at the firm level. The section also evaluates the potential increase in economic capital lenders may face in each of the scenarios. Finally, section 6 presents the conclusions and suggests other uses of the mapping not explored here.

\section{Equity prices and probability of default: anecdotal evidence}

The Covid-19 pandemics has raised concerns on the potential overvaluation of stocks markets relative to the current economic outlook (BIS, 2020; IMF, 2020). After experiencing large drops in value in March 2020, stock markets worldwide bounced back strongly. In many countries, stock market valuations stood at historical record high levels, as has been the case in the United States (Figure 1). Were observers using market valuations exclusively to judge the impact of the pandemics, 2020 would have been the shortest recession ever experienced in history.

Figure 1. United States: market value and 1-year risk-free rate

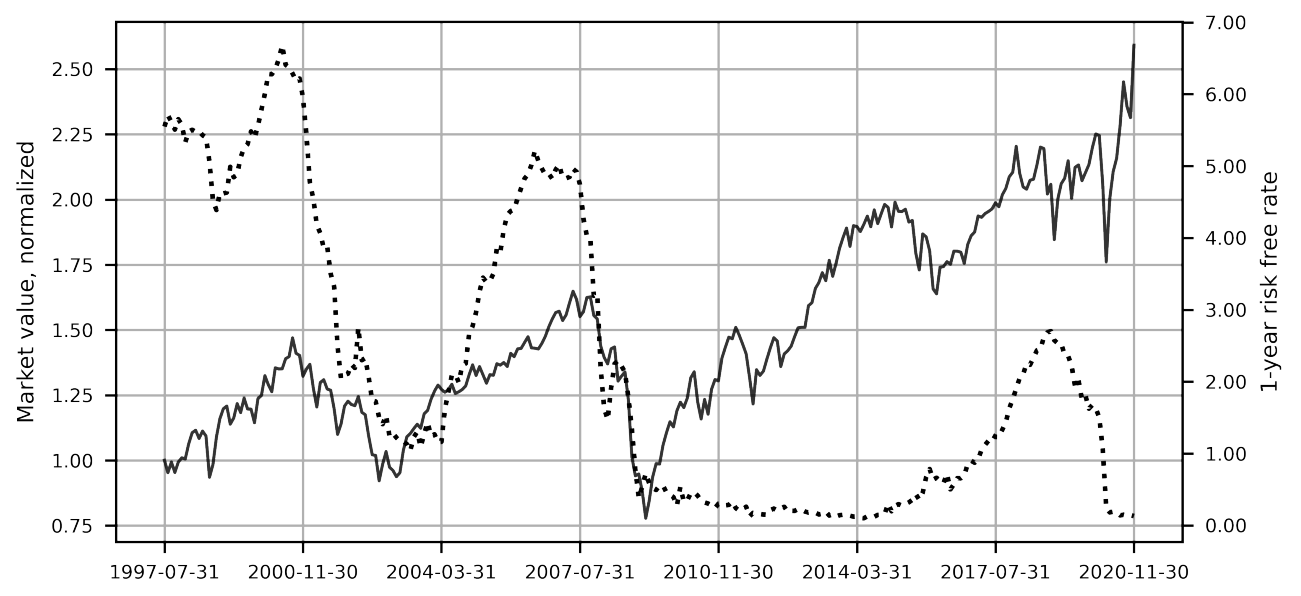

Normalized market value computed as the mean market value of publicly listed corporations relative to its July 31, 1997 value. Solid line: market value, left axis; dotted line: 1-year risk-free rate, right axis. Source: Datastream and author's calculations.

Economic fundamentals paint quite a drastic and different picture. In January 2021 the IMF projected that world real GDP growth fell to 2.8 percent in 2020 down from 3.5 percent in the previous year. Advanced economies experienced a 5 percent decline. Emerging markets and developing economies fare a bit better, down only by 2.4 percent. However, the success of several Asian countries in containing the pandemics offset larger losses elsewhere in the emerging markets universe - India and Latin America recorded contractions of 8 percent and 7.4 percent respectively.

Several factors might have been contributed to a buoyant stock market despite the lackluster economic conjuncture. One factor, cited quite often, is that low rate policies central banks have pursued since the onset of the global financial crisis in 2008-2009 have been a major driver of equity prices. In the United States the data suggests this has been the case after 2009 (Figure 1). In fact, there seems to be two episodes, January 
2009-December 2015 and the year 2020, during which the stock market posted a strong performance as rates decline (Figure 2). During these two episodes, the rates were at record low levels below 1 percent. ${ }^{4}$

Figure 2. United States: market value and 1-year risk-free rate: historical episodes

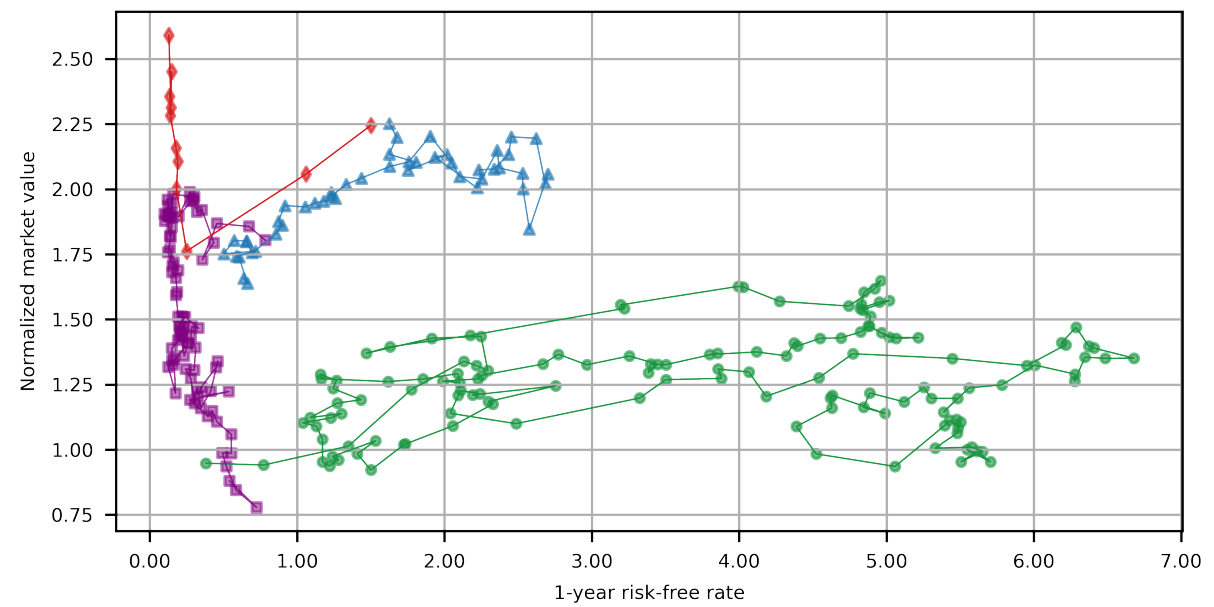

Normalized market value computed as the mean market value of publicly listed corporations relative to its July 31, 1997 value. Green circles: Jan. 1997-Dec. 2007; purple squares: Jan. 2009-Dec. 2015; blue triangles: Jan. 2015-Dec. 2019; red diamonds: Jan. 2020-Dec. 2020. Source: Datastream and author's calculations.

High equity valuations by end-2020 could have concealed rising corporate sector risk. Low funding costs have enabled further borrowing and indebtedness in the corporate sector, raising anxiety about solvency risk going forward once Covid-related support measures are withdrawn (BIS, 2020; IMF, 2020). In 2020, equity markets responded negatively to the limited withdrawal of support measures (Chan-Lau and Zhao, 2020).

Figure 3. United States: market value and 1-year probability of default

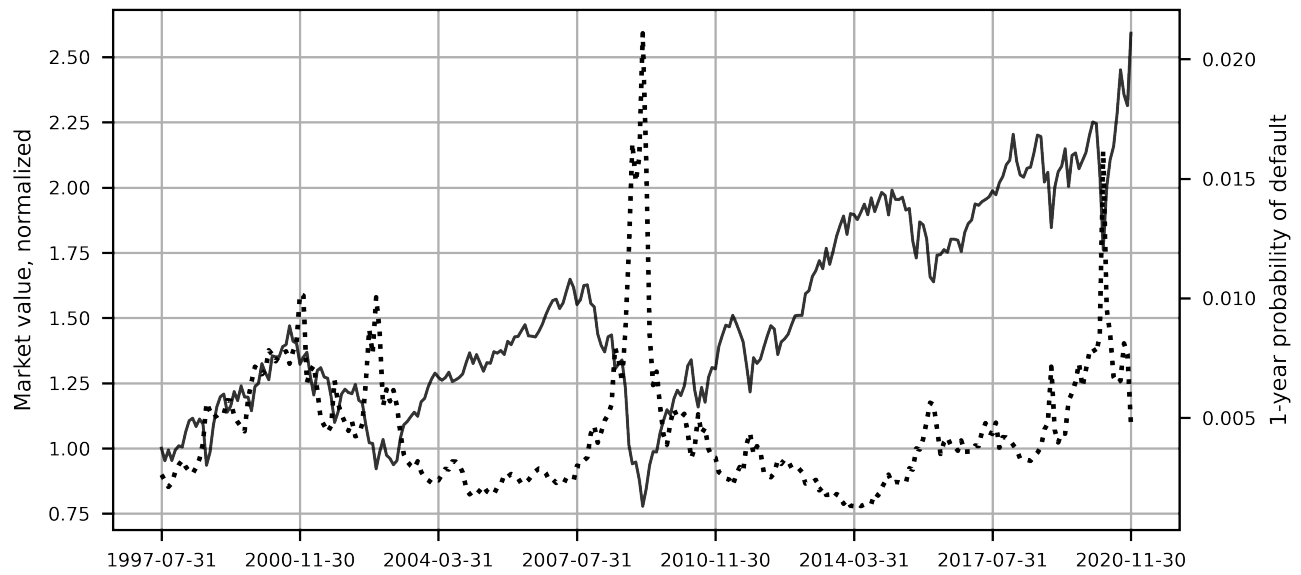

Normalized market value: solid line, left axis; 1-year probability of default: dotted line, right axis. Normalized market value computed as the mean market value of publicly listed corporations relative to its July 31, 1997 value. Source: Datastream (market value), Credit Research Initiative, National University of Singapore (probability of default), and author's calculations.

\footnotetext{
${ }^{4}$ The analysis uses the 1-year U.S. Treasury zero yield as the risk-free rate. Besides moving closely with the U.S. Federal Fund rates it also shows the yields investors could expect from holding a risk-free asset compared with the dividend yield accrued from investing in the stock market.
}

\section{CInternational Monetary Fund. Not for Redistribution}


Notwithstanding the trends above, equity prices in combination with other sources of information, such as financial statement data, are still useful for assessing corporate default risk. The mean 1-year probability of default (PD) for publicly listed firms in the United States have trended upwards since 2014 despite rising market valuations, a situation also experienced in the late 1990s (Figure 3). It does not follow, as business news commonly report, that higher equity valuations imply that markets are oblivious to default risk.

\section{The DD-PD Mapping: Building Blocks}

The construction of the DD-PD mapping follows standard of best practices in the management of credit portfolios that are at the root of successful commercial default risk services (Crosbie and Bohn, 2003; Bohn and Stein, 2009). Before performing the empirical estimation, it is necessary to choose:

- an appropriate equity-based risk measure,

- a rich $\mathrm{PD}$ database, and

- an estimation method suitable for constructing the mapping suitable to the data.

For the DD-PD mapping, the choices are the Black-Scholes-Merton (BSM) Distance-to-Default (DD); the corporate PD database of the Credit Research Initiative, National University of Singapore (CRI); and the quantile regression method. In a nutshell, for all firms' observations we collect their BSM-DD and the corresponding PDs, and create the mapping using quantile regression. The rationale for each of these choices is presented next.

\subsection{The Black-Scholes-Merton (BSM) Distance-to-Default (DD)}

Black and Scholes (1973) and Merton (1974) first drew attention to the insight that corporate securities are contingent claims on the asset value of the issuing firm. Given the seniority of the different claims on the assets of a firm, the market value of a firm's equity is equivalent to a call option as shareholders only accrue the residual value of the assets after debtholders are paid.

Under the assumption that the asset value of the firm follows a geometric Brownian motion, the market value, i.e. market capitalization, of the firm, $V$, can be set equal to the BSM call option price: ${ }^{5}$

$$
V=A \Phi\left(d_{1}\right)-D \exp (-r T) \Phi\left(d_{2}\right)
$$

where

$$
\begin{aligned}
& d_{1}=\frac{\log (A / D)+\left(r+\frac{1}{2} \sigma^{2}\right) T}{\sigma \sqrt{T}}, \\
& d_{2}=d_{1}-\sigma \sqrt{T}
\end{aligned}
$$

$A$ is the asset value of the firm, $D$ is the default barrier, $r$ is the risk-free rate, $T$ is the time horizon of interest, and $\sigma$ is the asset volatility. Some of the variables in the formula can be observed in the market, some can be calibrated using market and financial statement data, and some have to be reverse-engineered from equation (1).

In standard applications, $V$ is observed in the market and the risk-free rate is set equal to that of a safe asset with a maturity equal to the time horizon analyzed. For U.S. based firms, the safe assets used are U.S. Treasury bills or bonds. Determining the value of the default barrier is more involved and set equal to the

\footnotetext{
${ }^{5}$ For accesible textbook treatments see Lando (2004) and Bohn and Stein (2009).
} 
book value of short term debt, i.e. debt maturing within one year,plus half the book value of long term debt (Bohn and Crosbie, 2003).

The values of two variables, the asset value $A$ and the asset volatility $\sigma$ are not observable but can be obtained reverse-engineering equation (1) given time series of $N$ observations of the firm's market capitalization $V_{1}, V_{2}, \ldots, V_{N}$, equally spaced in time by $\Delta t$. Maximum likelihood methods such as those presented in Duan (1994) could be used to estimate the asset value and volatility. This paper uses instead the iterative method introduced in Vassalou and Xing (2003) due to it ease of implementation. Lando (2004) reports results using the iterative method tend to be similar to those using maximum likelihood. The next box describes in detail the Vassalou and Xing algorithm.

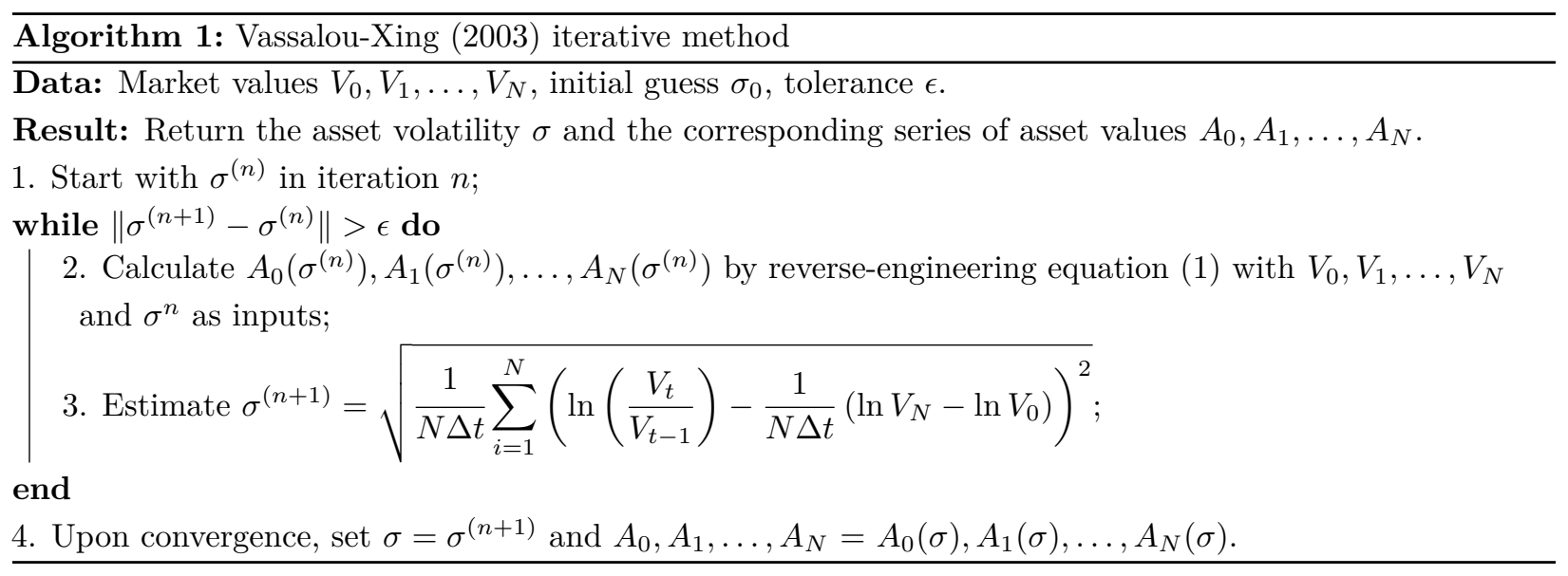

Once the values of all the variables are either calibrated or estimated, it becomes possible to compute the the BSM DD, an equity-based method popularized by the company KMV (now part of Moody's Analytics) and that served as the basis of its Expected Default Frequency algorithm (Crosbie and Bohn, 2003):

$$
D D=\frac{\log \left(\frac{A}{D}\right)+\left(r-\frac{1}{2} \sigma^{2}\right) T}{\sigma \sqrt{T}} .
$$

The DD is used as one of the inputs in the construction of the DD-PD mapping. It has an intuitive appeal: if the asset value follows a geometric Brownian motion with drift and volatility equal to the risk-free rate, $r$ and $\sigma$ respectively, by time $T$ the probability that the asset value is lower than the default barrier $D$ is equal to $\Phi(-D D)$. In practice, the DD is not used to infer the PD directly but rather to rank the firms in terms of riskiness. Once the rankings are established, empirical mappings to default rates, or directly to PDs, as done here, are used to associate them to objective measures of default risk. ${ }^{6}$

\subsection{Forward Intensity-based Probabilities of Default (CRI-PDs)}

The second basic building block of the DD-PD mapping is the PD database of the Credit Research Initiative at the National University of Singapore. The database covers 73,000 publicly listed firms in 133 countries. It includes dead (delisted) and live firms which removes survival bias from the analysis. The dataset, going back to 1990, is updated daily for over 36,000 firms and is available to researchers upon registration. Given the

\footnotetext{
${ }^{6}$ Bohn and Stein (2009) discuss Moody's Analytics use of the DD; Duan and Wang (2012) discuss differences in the DD estimation of financial and non-financial firms.
} 
large number of firms and default events the database covers, it is suitable for creating a reliable mapping between DDs and PDs.

The PDs in the CRI database are computed using the forward-intensity model of Duan, Sun, and Wang (2012), or CRI-PD model. ${ }^{7}$ The model considers two independent doubly stochastic Poisson processes, one for delisting (exits) due to default events and the other for delisting due to other reasons. The CRI-PD incorporates sixteen (16) input covariates including macro-financial and firm-specific factors constructed using market and financial statement data collected from Thomson Reuters Datastream and Bloomberg Data License Back Office Product (see Table 1). ${ }^{8}$

Table 1. CRI PD model: covariates

\begin{tabular}{|c|c|}
\hline Covariate & Description \\
\hline \multicolumn{2}{|l|}{ Macro-financial factors } \\
\hline Stock index return & Trailing 1-year return of the prime stock market \\
\hline Short-term risk-free rate & 3-month government bill yield \\
\hline Economy-wide CRI-DD, financial firms & Median Distance-to-Default of financial/non-financial \\
\hline Economy-wide CRI-DD, non-financial firms & $\begin{array}{l}\text { firms in each economy inclusive of foreign firms listed } \\
\text { in the economy's exchange }\end{array}$ \\
\hline \multicolumn{2}{|l|}{ Firm-specific attributes } \\
\hline CRI-Distance-to-Default (level and trend) & $\begin{array}{l}\text { Volatility adjusted leverage based on Merton (1974) } \\
\text { applying CRI modified parameter adjustment } \\
\text { calculations }\end{array}$ \\
\hline Cash-to-total assets (level and trend) & $\begin{array}{l}\text { For financial firms, the logarithm of the ratio of cash } \\
\text { and short-term investments to total assets }\end{array}$ \\
\hline $\begin{array}{l}\text { Current assets to current liabilities (level and } \\
\text { trend) }\end{array}$ & $\begin{array}{l}\text { For non-financial firms, the logarithm of the ratio of } \\
\text { current assets to current liabilities }\end{array}$ \\
\hline Net income to total assets (level and trend) & Profitability indicator \\
\hline Relative size (level and trend) & $\begin{array}{l}\text { Logarithm of the ratio of a firm's market } \\
\text { capitalization to the median market capitalization in } \\
\text { the economy }\end{array}$ \\
\hline Relative market-to-book ratio & $\begin{array}{l}\text { Captures a firm's market misvaluation relative to } \\
\text { future growth opportunities; measured relative to the } \\
\text { economy's median level }\end{array}$ \\
\hline Idiosyncratic volatility & $\begin{array}{l}\text { 1-year standard deviation of the residuals after } \\
\text { regressing market capitalization against the economy's } \\
\text { stock return (Shumway, 2001) }\end{array}$ \\
\hline
\end{tabular}

Source: CRI (2019b, 2020).

The CRI-PD model relies on a corporate events database comprising more than 6,000 default events and 43,000 other exit events since 1990. The corporate events are gathered from numerous sources, including

\footnotetext{
${ }^{7}$ For the full details of the model, see the cited article; for the technical implementation in the database, see Duan and Fulop (2013) and CRI (2020).

${ }^{8}$ The definition of the DD in the CRI-PD model is slightly different from the one used here; mainly due to a different specification of the default barrier and the estimation methodology (CRI, 2020). We will refer to this DD as CRI-DD.
} 
Bloomberg, Compustat, CRSP, Moody's reports, exchange web sites, and news sources. The default events fall into one of the following classes: ${ }^{9}$

- Bankruptcy filing, receivership, administration, liquidation or any other legal impasse to the timely settlement of interest and/or principal payments;

- A missed or delayed payment of interest and/or principal, excluding delayed payments made within a grace period;

- Debt restructuring/distressed exchange, in which debt holders are offered a new security or package of securities that result in a diminished financial obligation (e.g., a conversion of debt to equity, debt with lower coupon or par amount, debt with lower seniority, debt with longer maturity).

For calibration purposes, economies are collected into four different groups since there might not be enough defaults for some small countries. The North America group includes Canada and the United States; the Asia-Pacific Developed economies include Australia, Hong Kong SAR, Japan, Singapore, South Korea, Taiwan, and New Zealand. All European countries are included in a single calibration group, and emerging market countries worldwide are in another separate group. The CRI-PD models for China and India are calibrated separately for each country.

Table 2 reports the prediction accuracy of the CRI-PD model for each calibration group. The calibration is based on in-sample tests, using data until the end of the selected data sample and then comparing the forecasts to actual defaults occurring during the forecast horizon starting immediately after the end point of the data sample.As an example, one-year PD forecasts are made for 31 December, 2000 by using the data at or before that date and the corresponding parameters from the calibration. These PD forecasts are then compared to actual defaults that occurred at any time in 2001. The accuracy ratio (AR) and area under the receiver operating characteristic (AUROC) are comparable to those reported by other commercial risk providers. As expected, accuracy is better for advanced economies and shorter forecasting horizons.

Table 2. CRI model: prediction performance at different horizons

\begin{tabular}{|c|c|c|c|c|c|c|c|c|}
\hline \multirow[b]{2}{*}{ Region } & \multicolumn{4}{|c|}{$\mathrm{AR}$} & \multicolumn{4}{|c|}{ AUROC } \\
\hline & 1 month & 1 year & 2 year & 5 year & 1 month & 1 year & 2 year & 5 year \\
\hline China & 0.698 & 0.669 & 0.647 & 0.588 & 0.849 & 0.836 & 0.826 & 0.801 \\
\hline India & 0.730 & 0.694 & 0.670 & 0.592 & 0.865 & 0.848 & 0.838 & 0.802 \\
\hline Developed Asia-Pacific & 0.864 & 0.759 & 0.676 & 0.532 & 0.932 & 0.879 & 0.839 & 0.768 \\
\hline Emerging markets & 0.802 & 0.752 & 0.690 & 0.541 & 0.901 & 0.876 & 0.846 & 0.774 \\
\hline Europe & 0.870 & 0.753 & 0.644 & 0.485 & 0.935 & 0.877 & 0.823 & 0.745 \\
\hline North America & 0.943 & 0.855 & 0.759 & 0.595 & 0.971 & 0.928 & 0.881 & 0.801 \\
\hline
\end{tabular}

Source: CRI (2020).

\subsection{Quantile Regression}

Figure 4, left panel, shows the typical pattern of the scatter plot of the DD against the logarithm of the PD, in this case that of the oil and gas sector in the United States. Lower values of the DD correspond to higher PDs (less negative log PDs). For a fixed DD, the PD can take a wide range of values. This is not surprising as in the DD calculation only accounts for the asset value of the firm, its volatility, market value, and the

\footnotetext{
${ }^{9}$ See CRI (2020), Tables A.9 and A.10, for a complete listing of the default and other exits events.
} 
risk-free rate. Profitability and liquidity measures, as well as the cyclical stage of the industry sector and the economy are factored only indirectly through their impact on the market value.

Figure 4. United States: DD vs. log CRI-PD, oil and gas sector
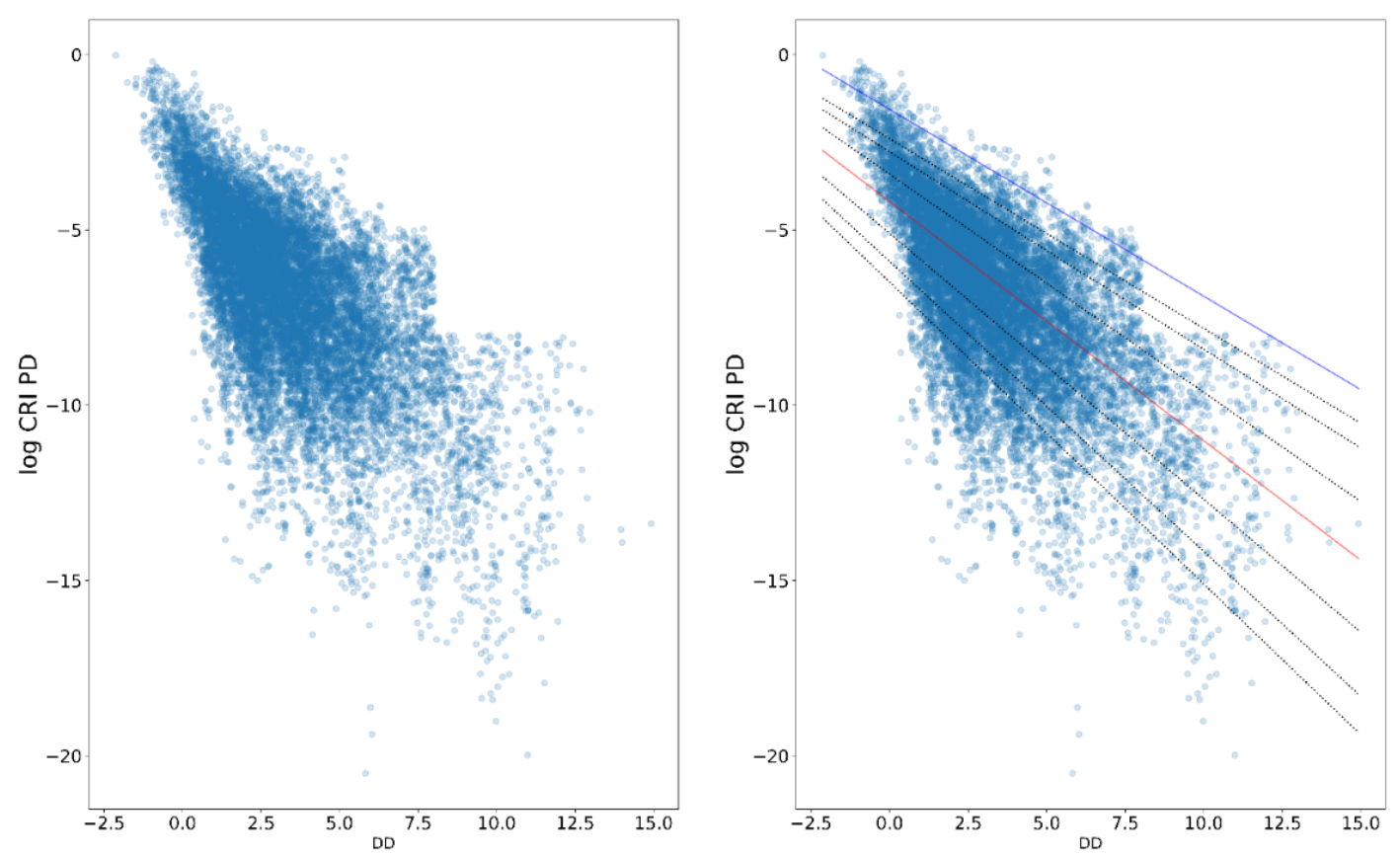

Straight lines in the right panel shows quantile regression lines calculated for the following quantiles, $\tau=$ $(0.05,0.10,0.25,0.50,0.75,0.90,0.95,0.99)$. The solid red line shows the median quantile regression, the solid blue line the 99 percentile regression. Source: CRI, Datastream and author's calculations.

Quantile regression is helpful in this situation. The method, introduced by Koenker and Basset (1978), offers a simple way to differentiate the PD response according to different risk regimes. We could argue that for a given DD, a riskier regime generates a higher PD. Figure 4, right panel shows quantile regression lines estimated for quantiles ranging from the 5 percentile to the 99 percentile for the oil and gas and sector in the United States. Higher quantile regression lines, closer to the zero horizontal line, correspond to riskier regimes. In general, for a set $T$ of $N$ quantiles sorted in ascending order, $T=\left\{\tau_{1}, \tau_{2}, \ldots, \tau_{N}\right\}$, the regimes are sorted in ascending risk by the quantile regressions $Q R(\tau)$. The general specification for the linear quantile regressions, given $N$ observations, is:

$$
\log P D_{i}=\alpha_{0}(\tau)+\alpha_{1}(\tau) D D_{i}+\boldsymbol{X}^{T} \boldsymbol{\beta}(\tau)+\epsilon_{i} \equiv Q R_{\tau}\left(D D_{i}, \boldsymbol{X}\right) ; \quad \tau \in T, i=1, \ldots, N
$$

where $\boldsymbol{X}$ is a set of cyclical indicators suitable for the economy or sector analyzed, as explained in more detail in the applications section below.

\section{Establishing the baseline quantile regression}

The risk regime interpretation of the quantile regression prompts the question on what risk regime is the relevant one at any given period. The observations of paired DD and PDs do not necessarily fall in the same quantile regression line. For the analysis of shocks or stress scenario analysis, as explained in the sections below, it is necessary first to establish the most likely current risk regime, i.e. the baseline risk regime. 
This is accomplished by setting the baseline risk regime equal to the quantile regression line $Q R^{*}$ such that its quantile $\tau^{*}$ is the one that minimizes the sum of the squared difference between the quantile regression prediction of $\log P D$ and the observed $\left(D D_{i}, \log P D_{i}\right)$ pairs, $i=1, \ldots, N$ :

$$
\tau^{*} \equiv \underset{\tau}{\arg \min }\left\{\sum_{i=1}^{N}\left(Q R_{\tau}\left(D D_{i}, \boldsymbol{X}\right)-\log P D_{i}\right)^{2}\right\} .
$$

Note that the baseline risk regime can be estimated for individual firms, a portfolio of firms, sector-wide, a group of sectors, or economy-wide. The next section explains how to combine the three building blocks to perform scenario analysis.

\section{Scenario Analysis with the DD-PD model}

The DD-PD mapping is a granular mapping that permits modeling the impact of scenarios on individual firms. The flexibility derived from the mapping granularity allows the analysis of scenarios under which not all firms need to be subject to the same shock and/or migrate to the same risk regime. As an example, scenarios consistent with the greening of the economy imply that firms in the oil and gas sector might migrate to high risk regimes and those in the renewable energy sector might migrate to lower risk regimes.

Three types of scenario analysis are feasible. The first one deals with shocks in the baseline regime, the second with shocks in the stress regime, and the third onewith shocks in arbitrary risk regimes. Regardless of its type, in each scenario analysis it is necessary to choose:

- the values of a primary set of four parameters needed in the DD calculation: the market value of the firm, the asset volatility of the firm, the risk-free rate, and the default barrier; these could be set at the firm level, sector and industry level, or economy-wide level;

- the values of variables other than the DD included in the QR estimation, i.e. the covariate set $\boldsymbol{X}$; they typically apply to all firms equally;

- the choice of risk regime prevalent in the scenario analysis and the firms' risk regime migration; it is not necessary that all firms start from the same risk regime and/or that they migrate to the same risk regime.

The scenario values of the DD parameters and other variables in the QR estimation could be obtained from empirical/quantitative models or when not enough data and/or time are available for an exhaustive data analysis, from educated guesses consistent with economic narratives and past historical events. Expert judgment would typically guide the choice of the scenario risk regime.

\subsection{Baseline risk regime analysis}

A shock in the baseline risk regime assumes that the firm remains in the current risk regime, as defined in equation (4). As noted above, a firm's current observation pair $(D D, P D)$ may not fall exactly on the baseline regime. The analysis of the shock requires mapping the impact of the shock onto the baseline risk regime and to extrapolate to the observed PD, as explained in detail in Algorithm 2 and summarized graphically in Figure 5, left panel. 


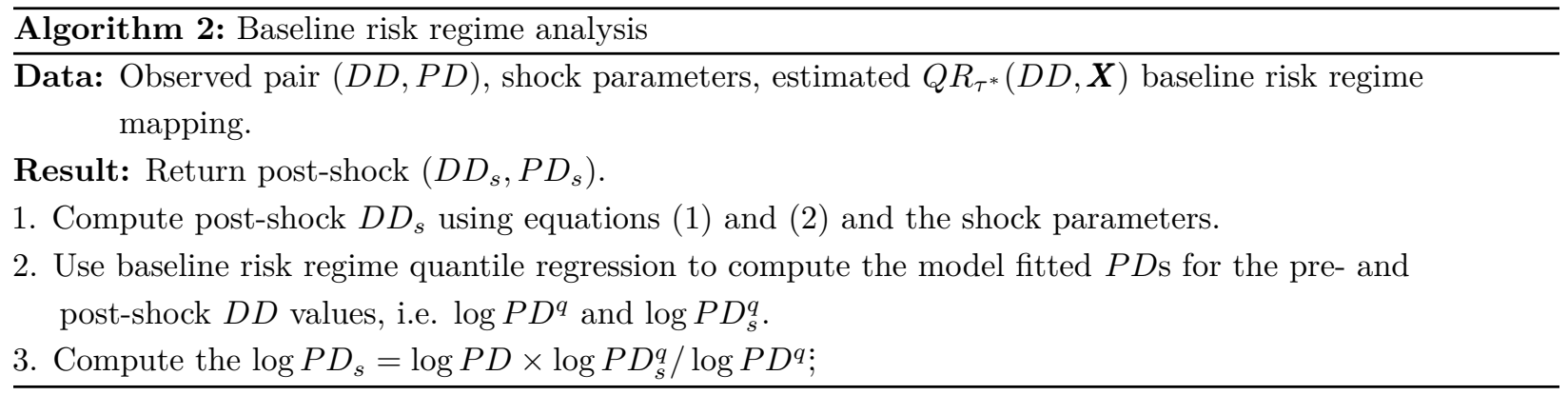

\subsection{Stress analysis}

The stress analysis (or the stress test) assumes that after the shock, the firm migrates from the baseline risk regime line to a higher risk regime line, i.e. the 95 percentile quantile regression line. The calculation of the post-shock PD is similar to the baseline risk regime analysis but takes into account the risk regime migration, as detailed in Algorithm 3 and shown in Figure 5, right panel.

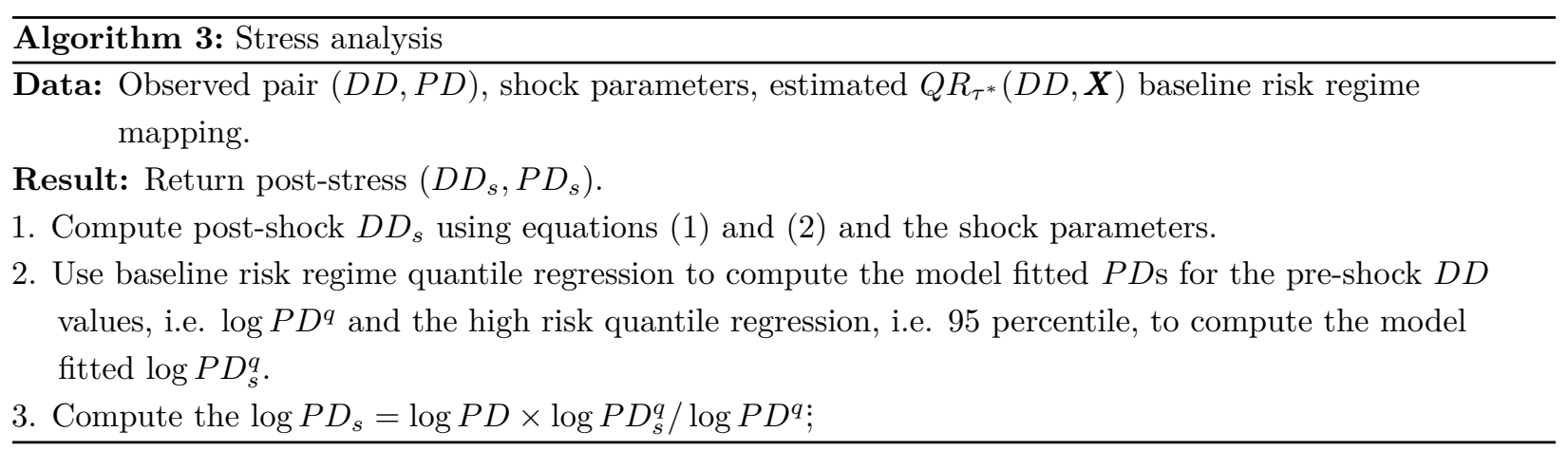

Figure 5. Scenario analysis: baseline risk regime shock and stress analysis

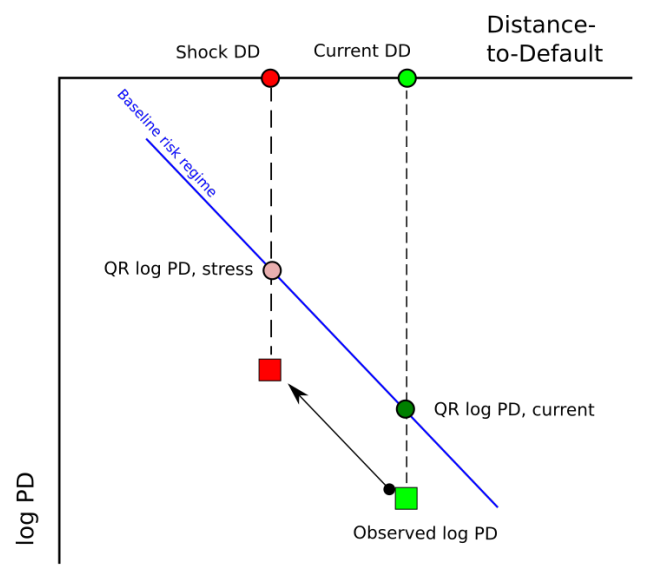

(a) Baseline risk regime shock

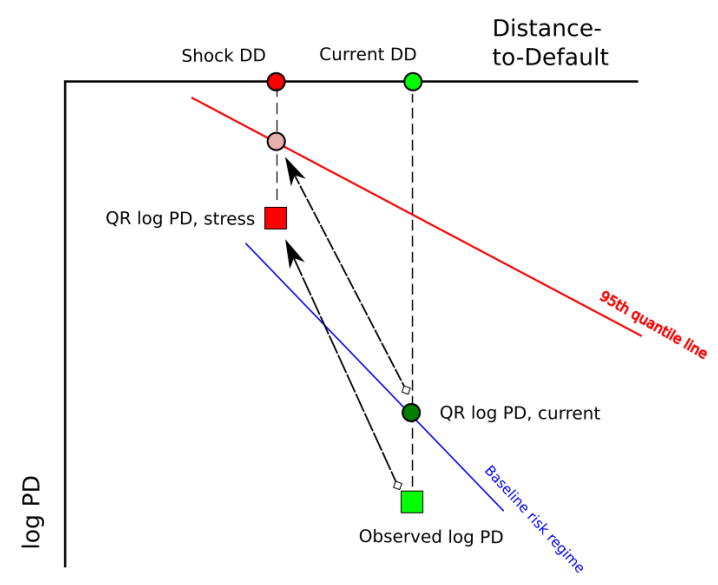

(b) Stress analysis

\subsection{Arbitrary risk regime analysis}

Algorithm 3 also applies for scenario analysis contemplating firms migrating to a risk regime, i.e. QR line, different from the current one. All that is needed is to specify the desired risk regime, i.e. quantile. For 
instance, while the stress analysis emphasizes downside risk scenarios, the analyst may want to consider upside scenarios involving firms migrating to low risk regimes.

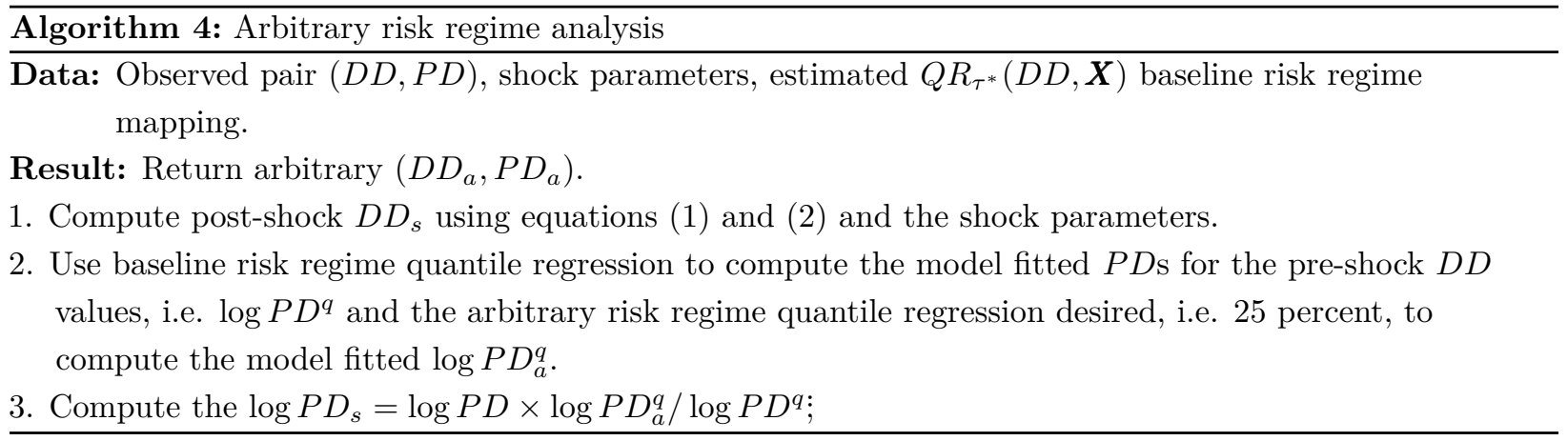

The next section uses algorithms 2 and 3 to perform baseline risk regime and stress analyses of corporate default risk in the United States under different market correction scenarios.

\section{Scenario Analysis: Corporate Sector Risk in the United States}

\subsection{Scenarios}

Market corrections and increased volatility could hurt the viability of U.S. corporations. This section uses the DD-PD model to evaluate the impact of shocks in three what-if scenarios characterized by stock price declines and increased asset volatility:

\section{Stock market and volatility shock scenarios}

- Scenario 1: a broad market correction of and an increase in asset volatility by 10 percent,

- Scenario 2: a broad market correction of and an increase in asset volatility by 20 percent, and

- Scenario 3: a broad market correction of and an increase in asset volatility by 30 percent.

The scenarios are used to perform baseline risk regime and stress analyses using the methods described earlier. The stress analysis set the stress regime equal to the $95^{\text {th }}$ quantile regression with the current date set to end-December 2020. To put the results in context notice that the price correction in the third scenario is similar to the stock market correction observed after the bursting of the 2000 dotcom bubble in the United States.

\subsection{Data and Estimation}

The data used in the analysis covers over 4600 publicly listed firms, including dead and currently listed firms during the sample period August 1985-December 2020. For each firm monthly data on market value, shortterm and long-term liabilities was collected from Thomson Reuters. The corresponding 1-year probability of default time series for each firm were sourced from the Credit Research Initiative at the National University of Singapore. The 1-year risk free rate was set equal to the yield of the 1-year U.S. Treasury bill.

On a given date, asset values and volatilities were calculated using the observations in the past 60-month period. In case that less than less than 60 observations were available for the calculation, the estimation used all the past observations as long as there were at least 12 monthly data points. Because of the 60 -month horizon estimation period, the asset volatilities correspond to a medium to long-term horizon, i.e. medium-term asset volatilities. 
Short-term and long-term liabilities are reported on a quarterly basis. In between quarterly reports it was assumed that liabilities did not change. The original raw dataset comprised about 9 million observations. After the data was processed there were about 700,000 observations usable observations.

Six cyclical indicators, all seasonally adjusted, were included in the estimation of the quantile regressions underlying the PD-DD mapping:

- the Conference Board Leading Economic Index,

- the Capacity Utilization Index,

- the Consumer Confidence Index,

- the ISM Non-Manufacturers' Survey Index,

- the ISM Purchasing Managers' Index,

- and the unemployment rate.

The PD-DD mapping was estimated individually for 65 industrial subsectors, which could then be aggregated into nine industrial sectors (Table 3) and for the following quantiles: 5, 10, 25, 50, 75, 90, 95, and 99.

Table 3. United States: industrial sectors and their subsectors

- Basic materials (88 firms): Chemicals, Forest Products and Paper, Iron/Steel, Mining.

- Communications (174 firms): Advertising, Internet, Media, Telecommunications.

- Consumer, Cyclical (362 firms): Airlines, Apparel, Auto Manufacturers Auto Parts and Equipment, Distribution/Wholesale, Entertainment, Food Service, Home Builders, Home Furnishings, Housewares, Leisure Time, Lodging, Office Furnishings, Retail, Storage/Warehousing, Textiles, Toys/Games/Hobbies.

- Consumer, non-cyclical (661 firms): Agriculture, Beverages, Biotechnology, Commercial Services, Cosmetics/Personal Care, Food, Healthcare-Products, Healthcare-Services, Household Products/Wares, Pharmaceuticals.

- Energy (184 firms): Coal, Energy-alternate sources, Oil and Gas, Oil and Gas Services, Pipelines.

- Financial (805 firms): Banks, Diversified Finan Serv, Insurance, Investment Companies, Real Estate, Savings and Loans, Private Equity.

- Industrial (369 firms): Industrial Aerospace/Defense, Building Materials, Electrical Components and Equipment, Electronics, Engineering and Construction, Environmental Control, Hand/Machine Tools, MachineryConstruction and Mining, Machinery-Diversified, Metal Fabricate/Hardware, Miscellaneous Manufacturing, Packaging and Containers, Shipbuilding, Transportation, Trucking and Leasing.

- Technology (242 firms):Computers, Office/Business Equipment, Semiconductors, Software.

- Utilities (68 firms): Electric, Gas, Water.

Source: Credit Research Initiative, National University of Singapore.

Table 4 presents the descriptive statistics of the PDs grouped by industrial sectors at end-December 2020 . The sectoral mean PD is greater than the median PD, showing that the PD distribution is positively skewed and signaling the presence of fat right tails. The maximum PD shows the presence of outliers, with PDs 10 to 100 times above the $75^{\text {th }}$ percentile. The interquartile range shows that energy is the riskiest sector. 
Table 4. United States: descriptive statistics, probabilites of default (in bps)

\begin{tabular}{lccccccc}
\hline Sector & & & & & Standard & $25^{\text {th }}$ & $75^{\text {th }}$ \\
& Mean & Median & Minimum & Maximum & deviation & percentile & percentile \\
\hline Basic materials & 29.44 & 15.18 & 0.16 & 312.56 & 47.17 & 5.95 & 39.64 \\
Communications & 63.20 & 16.88 & 0.00 & 1614.18 & 151.32 & 5.82 & 56.15 \\
Consumer, cyclical & 65.47 & 28.88 & 0.00 & 1275.81 & 135.05 & 9.90 & 64.71 \\
Consumer, non-cyclical & 54.38 & 14.87 & 0.00 & 2436.95 & 172.13 & 3.64 & 45.88 \\
Energy & 183.05 & 90.15 & 1.39 & 4152.63 & 364.47 & 25.77 & 200.45 \\
Financial & 17.25 & 8.58 & 0.00 & 3068.51 & 110.41 & 3.83 & 15.19 \\
Industrial & 32.46 & 13.49 & 0.02 & 436.30 & 50.50 & 4.01 & 36.72 \\
Technology & 22.85 & 6.04 & 0.02 & 312.94 & 46.51 & 1.61 & 17.52 \\
Utiliities & 23.70 & 14.60 & 1.89 & 178.25 & 31.59 & 6.45 & 25.12 \\
\hline
\end{tabular}

Source: Credit Research Initiative.

\subsection{Results}

\section{Asset volatility and Leverage}

Figure 6 shows the mean asset volatility, estimated using the Vassalou-Xing algorithm, against the 1-year probability of default. Medium-term volatilities were high in the aftermath of the 1997 Asian financial crisis and the 1998 Russian sovereign default but trended downwards afterwards. The spike in the probability of default during the 2008 global financial crisis was mainly due to the drastic stock market correction rather than to increased asset volatility. Quantitative easing, arguably, pressured medium-term volatility downwards until 2013. Since then asset volatility has been rising in line with the 1-year PD, offsetting the negative effect higher stock prices have on default risk.

Figure 6. United States: mean asset volatiilty and 1-year probability of default

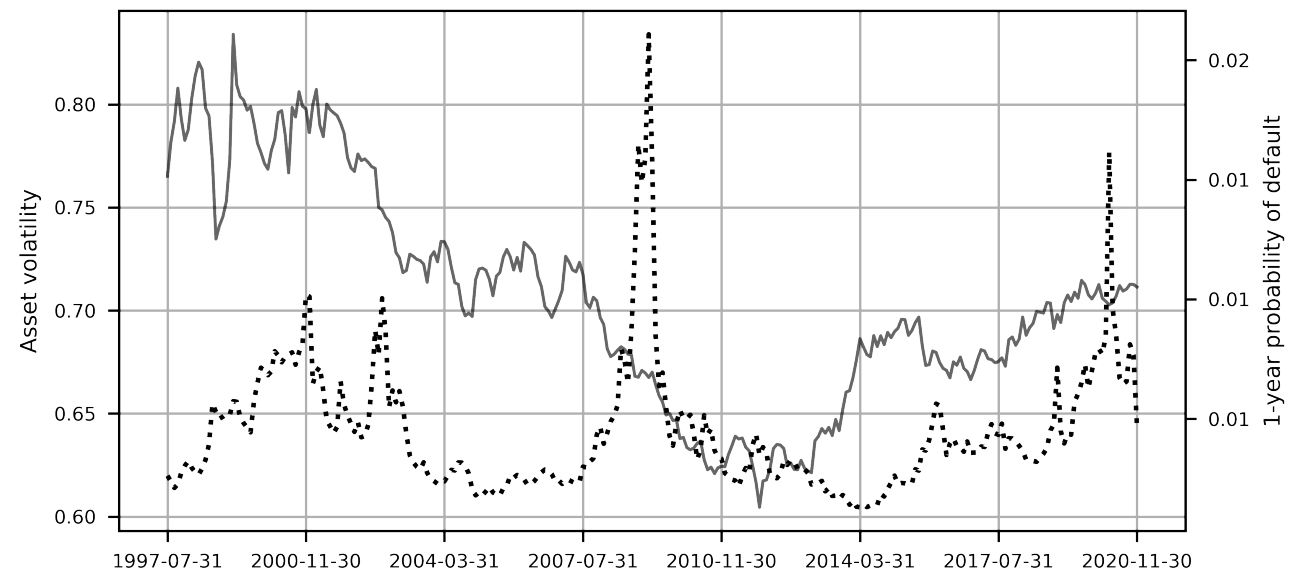

Source: Credit Research Initiative, National University of Singapore (probability of default), and author's calculations.

As of end-December 2020, asset volatility and leverage, measured as the ratio of the default barrier (short-term debt plus one half long-term debt) to the asset value, differ across sectors (Figure 7). The most volatile sectors of the economy are communications, consumer non-cyclical, energy, and technology. The upward pressure on PDs from high volatility is partly offset by lower leverage ratios in the non-cyclical and technology sectors, as 
equation (2) makes explicit. Remember, however, that each individual subsector has its own DD-PD mapping. Firms in different sectors are likely to have different PDs even if the value of their DD is the same.

Figure 7. United States: asset volatiilty and leverage
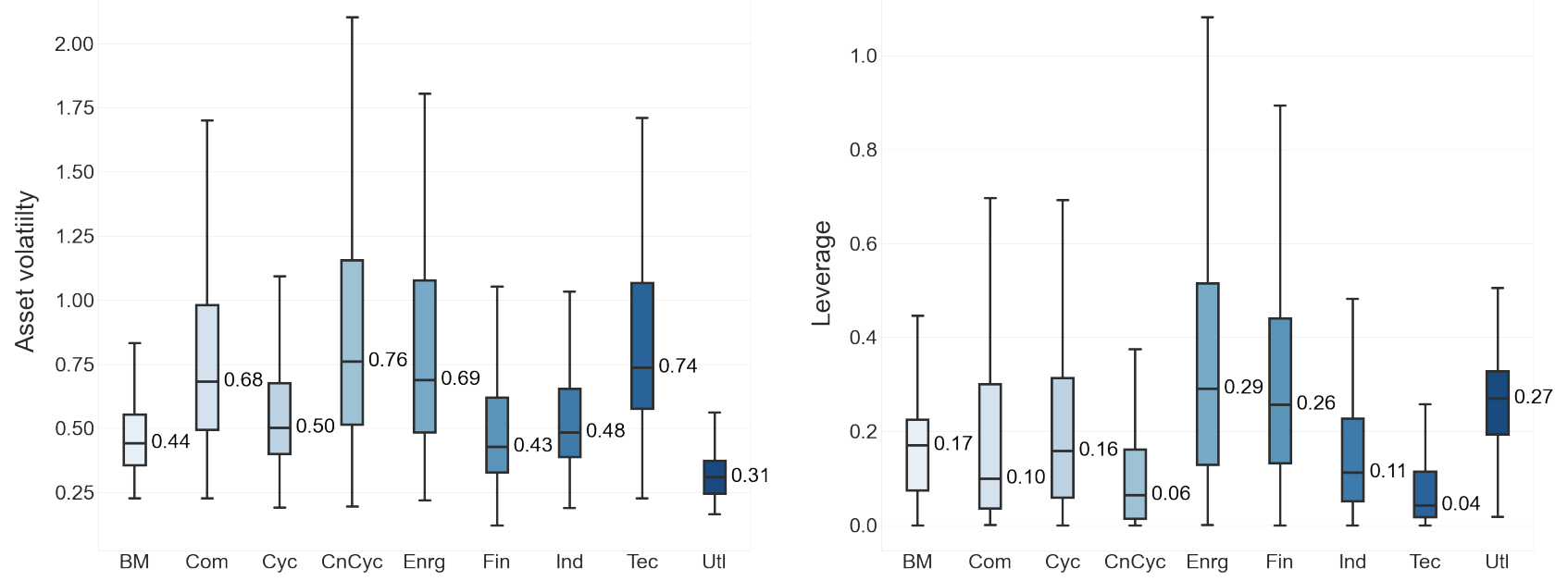

Leverage measured as the ratio of the default barrier to the asset value of the firm. BM: basic materials; Com: communications; Cyc: consumer cyclical; CnCyc: consumer non-cyclical; Enrg: energy; Fin: financial; Ind: industrial; Tec: technology; Utl: utilities. Source: author's calculations.

\section{Baseline risk regimes.}

Table 5 shows the baseline risk regimes of different industry groups as of end-December 2020, identified using equation (4).

Table 5. United States: industrial groups and baseline risk regime quantiles, December 2020

\begin{tabular}{|c|c|c|c|c|c|}
\hline Industry group & quantile & Industry group & quantile & Industry group & quantile \\
\hline Diversified Financial Services & 25 & Home Furnishings & 75 & Food & 90 \\
\hline Investment Companies & 25 & Housewares & 75 & Aerospace/Defense & 90 \\
\hline Real Estate & 25 & Healthcare Products & 75 & Engineering \& Construction & 90 \\
\hline Savings \& Loans & 25 & Building Materials & 75 & Hand/Machine Tools & 90 \\
\hline Auto Manufacturers & 50 & Electrical Components \& Equipment & 75 & Machinery-Diversified & 90 \\
\hline Home Builders & 50 & Electronics & 75 & Miscellaneous Manufacturing & 90 \\
\hline Textiles & 50 & Machinery-Construction \& Mining & 75 & Water & 90 \\
\hline Agriculture & 50 & Metal Fabricate/Hardware & 75 & Media & 95 \\
\hline Household Products/Wares & 50 & Packaging \& Containers & 75 & Retail & 95 \\
\hline Energy-Alternate Sources & 50 & Transportation & 75 & Toys/Games/Hobbies & 95 \\
\hline Banks & 50 & Trucking \& Leasing & 75 & Healthcare-Services & 95 \\
\hline Insurance & 50 & Computers & 75 & Pharmaceuticals & 95 \\
\hline REITS & 50 & Electric & 75 & Oil \& Gas Services & 95 \\
\hline Environmental Control & 50 & Gas & 75 & Pipelines & 95 \\
\hline Semiconductors & 50 & Mining & 90 & Office/Business Equipment & 95 \\
\hline Software & 50 & Airlines & 90 & Advertising & 99 \\
\hline Chemicals & 75 & Auto Parts \& Equipment & 90 & Apparel & 99 \\
\hline Forest Products \& Paper & 75 & Entertainment & 90 & Office Furnishings & 99 \\
\hline Iron/Steel & 75 & Leisure Time & 90 & Beverages & 99 \\
\hline Internet & 75 & Lodging & 90 & Coal & 99 \\
\hline Telecommunications & 75 & Biotechnology & 90 & & \\
\hline Distribution/Wholesale & 75 & Commercial Services & 90 & & \\
\hline
\end{tabular}

Source: Credit Research Initiative, National University of Singapore, and author's calculations. 
In general, the proposed method for selecting the baseline risk regime is consistent with industry news and investment analysts reports on industry performance. Industry groups related to construction, real estate, and financial services are in normal and low risk regimes, i.e. quantiles below or equal to the 50 percentile. But 3 of 4 of the industry sectors are in high risk regimes, especially groups related to apparel, office equipment, and energy (with the exception of green companies). ${ }^{10}$

\section{PD analysis}

Table 6 presents the liability-weighted PDs and implied S\&P ratings aggregated into nine industrial sectors at end-December 2020 and for each of the three scenarios in each of the regimes. The PDs are weighted by the firm's default barrier, i.e. short-term liabilities plus one half of the long-term liabilities.

Table 6. United States: weighted probabilities of default (in bps) and implied ratings

\begin{tabular}{|c|c|c|c|c|c|c|c|}
\hline \multirow[b]{2}{*}{ Sector } & \multirow[b]{2}{*}{ Dec. 2020} & \multicolumn{3}{|c|}{ Baseline risk regime } & \multicolumn{3}{|c|}{ Stress regime } \\
\hline & & Scenario 1 & Scenario 2 & Scenario 3 & Scenario 1 & Scenario 2 & Scenario 3 \\
\hline \multirow[t]{2}{*}{ Basic materials } & 22 & 30 & 48 & 73 & 82 & 117 & 161 \\
\hline & $\mathrm{BBB}$ & $\mathrm{BB}+$ & $\mathrm{BB}$ & $\mathrm{BB}$ & $\mathrm{BB}$ & $\mathrm{B}+$ & $\mathrm{B}+$ \\
\hline \multirow[t]{2}{*}{ Communications } & 27 & 34 & 45 & 59 & 54 & 71 & 90 \\
\hline & BBB- & $\mathrm{BB}+$ & $\mathrm{BB}+$ & $\mathrm{BB}$ & $\mathrm{BB}$ & BB- & BB- \\
\hline \multirow[t]{2}{*}{ Consumer, cyclical } & 63 & 77 & 98 & 124 & 137 & 170 & 206 \\
\hline & $\mathrm{BB}$ & $\mathrm{BB}$ & BB- & $\mathrm{B}+$ & $\mathrm{B}+$ & $\mathrm{B}+$ & $\mathrm{B}+$ \\
\hline \multirow[t]{2}{*}{ Consumer, non-cyclical } & 29 & 37 & 51 & 71 & 58 & 93 & 148 \\
\hline & $\mathrm{B}+$ & $\mathrm{B}+$ & $\mathrm{B}+$ & $\mathrm{B}+$ & $\mathrm{B}+$ & $\mathrm{B}+$ & $\mathrm{B}+$ \\
\hline \multirow[t]{2}{*}{ Energy } & 152 & 181 & 226 & 279 & 120 & 151 & 187 \\
\hline & $\mathrm{B}+$ & $\mathrm{B}+$ & $\mathrm{B}+$ & $\mathrm{B}+$ & $\mathrm{B}+$ & $\mathrm{B}+$ & $\mathrm{B}+$ \\
\hline \multirow[t]{2}{*}{ Financial } & 23 & 31 & 42 & 58 & 178 & 229 & 291 \\
\hline & BBB- & $\mathrm{BB}+$ & $\mathrm{BB}+$ & $\mathrm{BB}$ & $\mathrm{B}+$ & $\mathrm{B}+$ & $\mathrm{B}+$ \\
\hline \multirow[t]{2}{*}{ Industrial } & 25 & 36 & 59 & 93 & 75 & 116 & 168 \\
\hline & BBB- & $\mathrm{BB}+$ & $\mathrm{BB}$ & BB- & $\mathrm{BB}$ & $\mathrm{B}+$ & $\mathrm{B}+$ \\
\hline \multirow[t]{2}{*}{ Technology } & 17 & 23 & 36 & 55 & 89 & 125 & 169 \\
\hline & $\mathrm{BBB}$ & BBB- & $\mathrm{BB}+$ & $\mathrm{BB}$ & BB- & $\mathrm{B}+$ & $\mathrm{B}+$ \\
\hline \multirow[t]{2}{*}{ Utilities } & 23 & 36 & 64 & 105 & 112 & 172 & 247 \\
\hline & BBB- & $\mathrm{BB}+$ & BB & $\mathrm{B}+$ & $\mathrm{B}+$ & $\mathrm{B}+$ & $\mathrm{B}+$ \\
\hline
\end{tabular}

Weighted by default barrier values; implied ratings determined according to CRI (2019b). Source: author's calculations.

In general, in the baseline risk regime prompt ratings downgrades of one to two notches, and in the stress regime of up to five notches. Implied rating bands are quite wide and can disguise substantial changes in creditworthiness. For instance, in the stress regime the weighted implied rating stays flat at B+. Nevertheless, there is a 100 bps difference between the PD in the worst shock case, a 30 percent market correction, and the least severe shock, a 10 percent market correction.

Figures 7, 8 and 9 offer a more granular view of the PD distribution under the three scenarios. PD changes are computed at the individual firm level and then aggregated in their respective sectors.

\footnotetext{
${ }^{10}$ The analysis selects baseline risk regimes by industry group; if desired, different baseline risk regimes can be identified for individual firms even if belonging to the same industry group.
} 
Figure 7. United States, industrial sectors: PD distribution, baseline risk regime
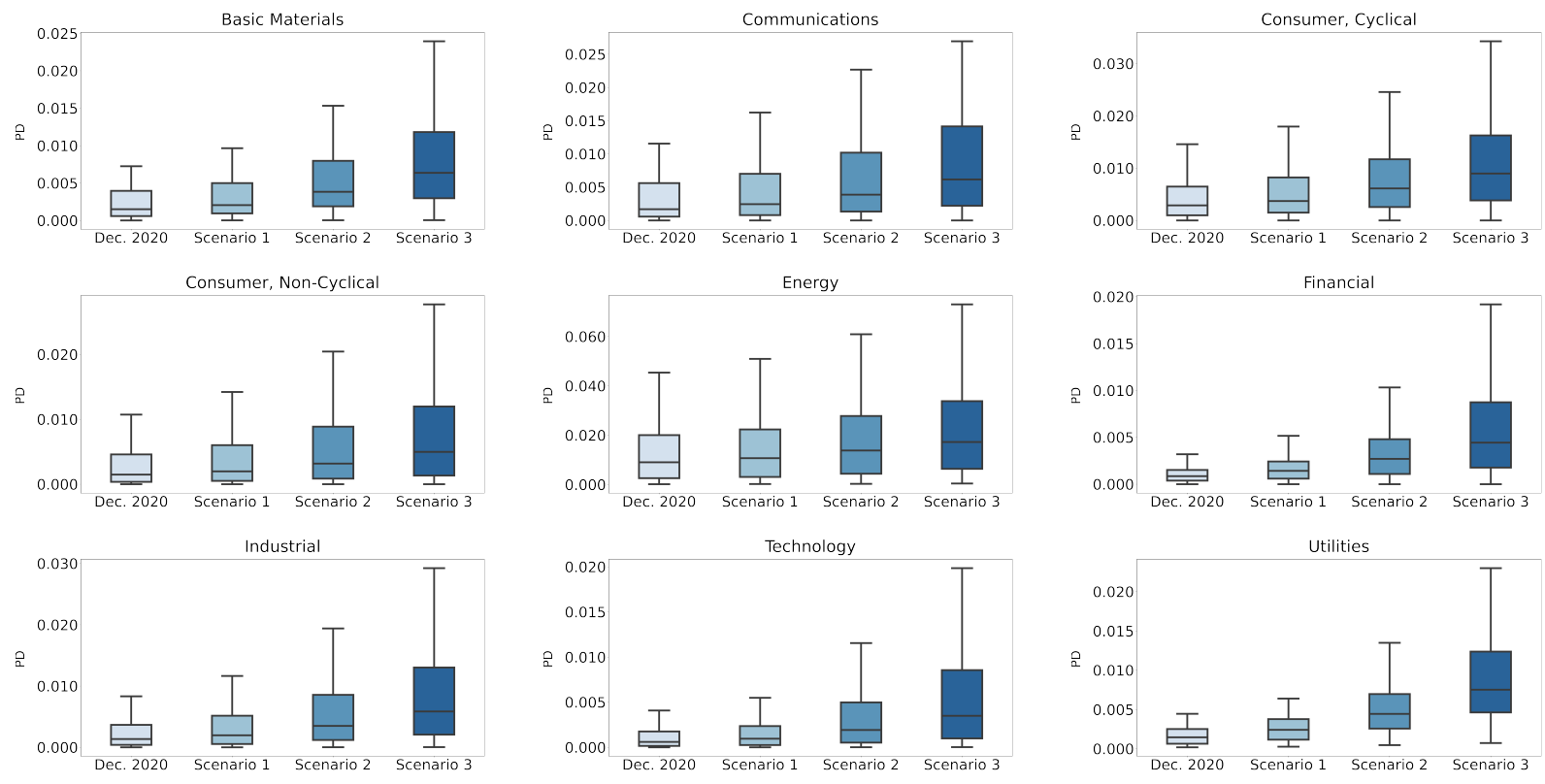

Source: author's calculations.

The first two figures show the sectoral PD distribution induced by the shocks. With just one exception, the PD distributions shift right and right tails become noticeably fatter under stock price and volatility shocks in the baseline risk and stress regimes. The exception is the energy sector when subject to shocks under the first scenario. In contrast to other sectors the PD distribution shifts to the left and narrows.

Figure 8. United States, industrial sectors: PD distribution, stress regime
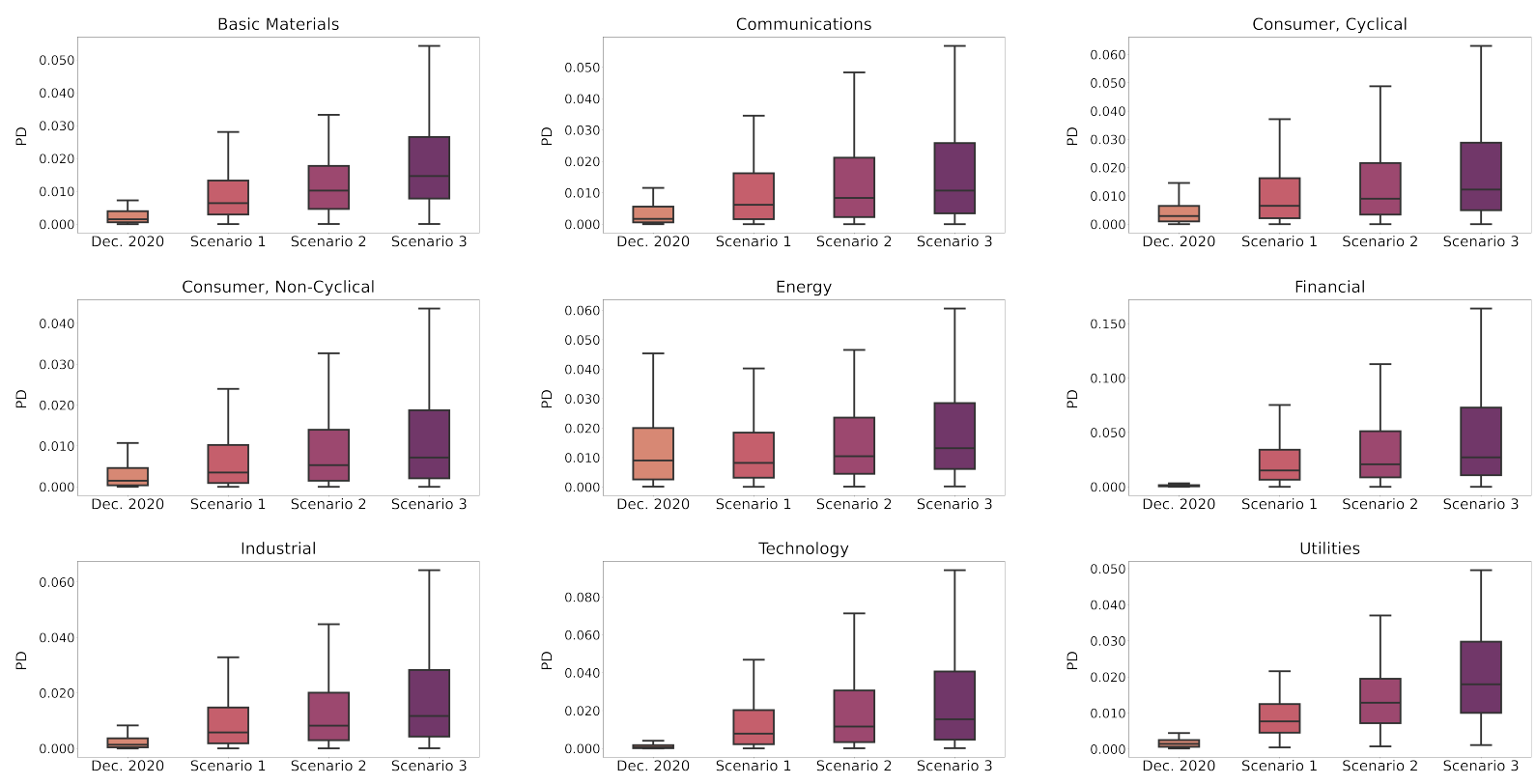

Source: author's calculations. 
The results are driven by the fact that the baseline risk regime of several of the constituent groups in the energy sector was the $99^{\text {th }}$ quantile regression, the highest risk regime considered in the analysis. The assumption that the stressed risk regime was the $95^{\text {th }}$ quantile regime implied the migration of many firms in the energy sector to a lower risk regime. This migration offset the stock price decline of 10 percent. In the other two scenarios the migration to a lower risk regime was not enough to counter-balance the more severe stock price declines of 20 percent and 30 percent respectively.

Figure 9 shows the increase in the sectoral median PDs relative to their end-December 2020 value as a result of the shocks in the two regimes. The technology and financial sectors are more sensitive to the shocks despite the fact that the former exhibits very low leverage and the latter low asset volatility. Drawing additional conclusions and inferences across industrial sectors is somewhat difficult since each sector has a different DD-PD mapping. Changes in DDs in one sector could yield substantially different changes in PDs compared with changes in other sector. Moreover, the DD-PD mapping is a bottom-up approach, as the results in one sector are aggregated from its individual firms. A full-fledged analysis may require looking at individual firms which are of particularly interest, i.e. systemic firms.

Figure 9. United States: median PD increase relative to December 2020 values

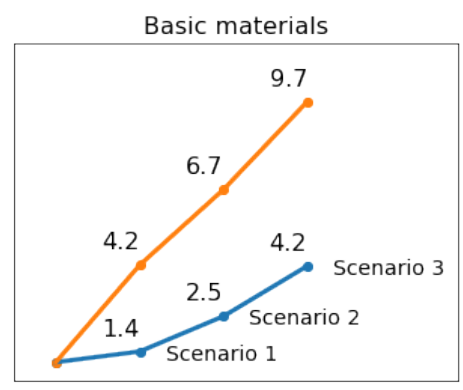

Consumer, non-cyclical
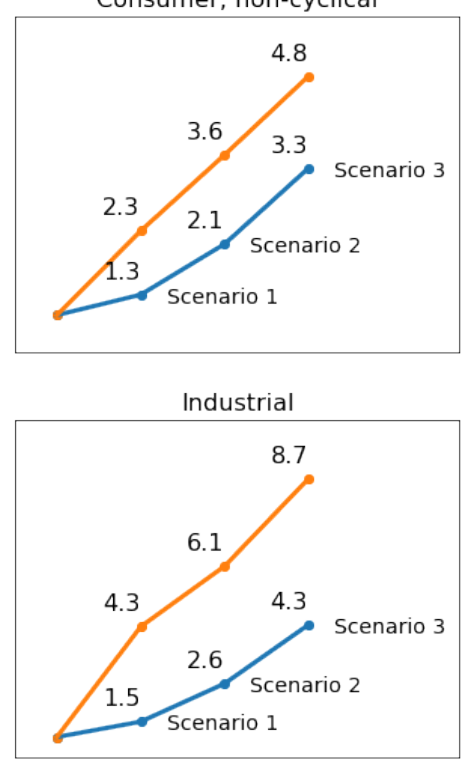

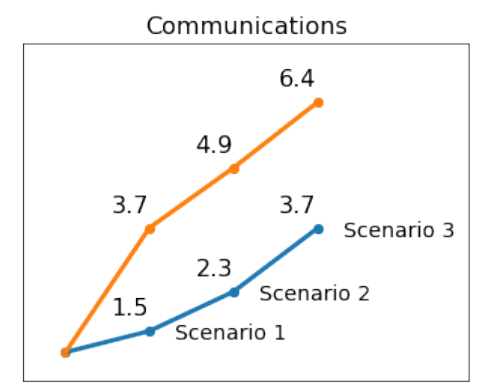

Energy
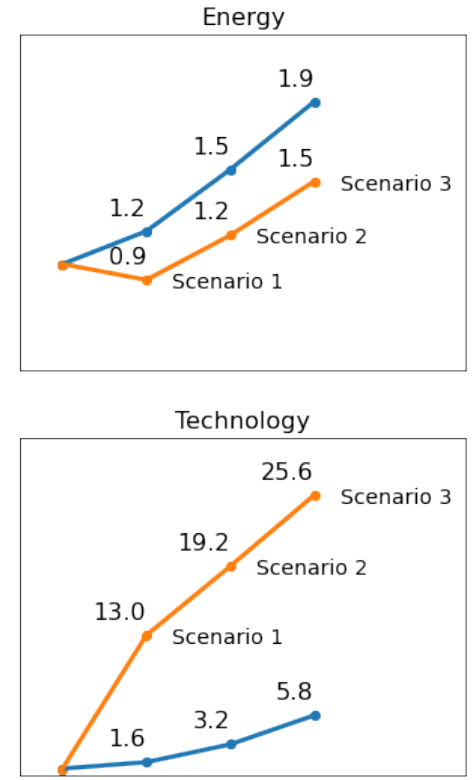
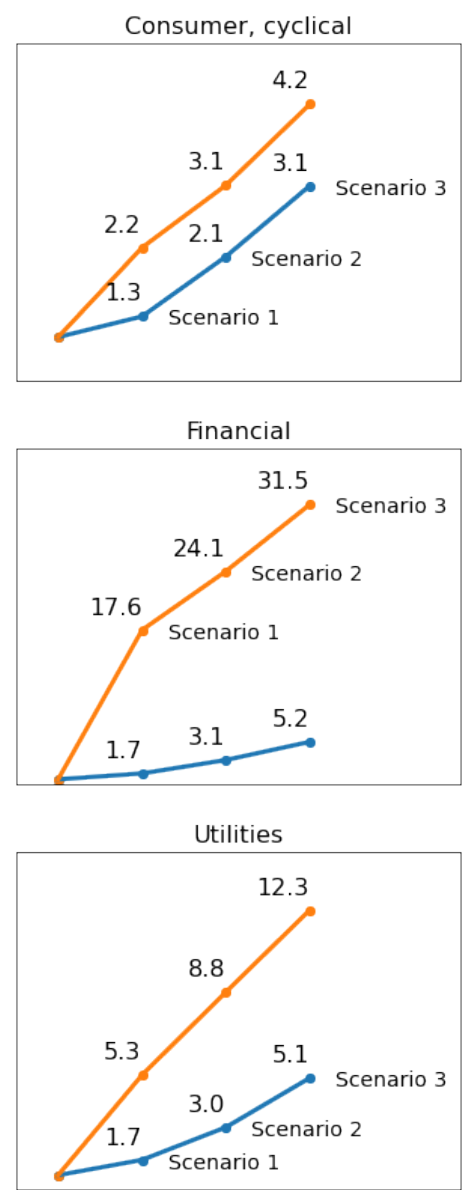

The figure shows the PD response to the shocks as a multiple of the PD's Dec. 2020 value. Blue line: baseline risk regime; orange line: stress regime. Source: author's calculations. 


\section{Economic capital in corporate loan portfolios}

At end-December 2020, the median 1-year PD in the U.S. corporate sector was relatively low at 10 bps, equivalent to S\&P BBB-rating. The global historical 1-year transition rate associated with this rating is 0.16 percent, a value roughly in line with the PD estimate (Kraemer et al., 2020). Given the low PD baseline, defaults per se may not be the main focus from a systemic risk perspective. Instead, the main concern would be the need of lending institutions to increase provisions and economic capital buffers in the corporate loan and credit portfolios. Failure to do so would induce forced delevering of the portfolios.

Even when no defaults occur higher PDs could impair corporations' access to credit. Lending institutions may curtail lending to maintain minimum regulatory capital requirements, institutional investors may reduce their exposure in case ratings fall below investment grade, and corporate hedging operations would become more expensive as rising counterparty credit risk drive margin requirements higher.

Capital requirements in this section are calculated using a simple version of the asymptotic risk factor model (ASRF) underlying the Basel II internal risk-based risk weight functions (BCBS, 2005) excluding maturity adjustments:

$$
K=L G D \times \Phi\left(\sqrt{1-R} \times \Phi^{-1}(P D)+\sqrt{R /(1-R)} \times \Phi^{-1}(0.999)\right)-P D \times L G D
$$

where $K$ is the capital requirement per unit of exposure, $L G D$ is the loss-given-default set equal to 40 percent, $R$ is the asset correlation of the assets in the portfolio, set equal to 30 percent, and $\Phi$ is the cumulative normal distribution.

Table 7 reports the required capital buffers as a multiple of their December 2020 values. The latter were calculated assuming that capital requirements are set equal to those corresponding to the end-December 2020 PD values. These calculations could understate capital requirements if the lending firm calculates capital requirements using a through-the-cycle approach. A quick glance at Figure 3, however, shows that the end-December 2020 average PD is approximately equal or slightly above its 10-year average suggesting the December 2020 estimates herein are appropriate.

Table 7. United States: Median economic capital requirements, as multiple of December 2020 values

\begin{tabular}{lcccccc}
\hline Sector & \multicolumn{3}{c}{ Baseline } & \multicolumn{3}{c}{ Stress } \\
& Scenario 1 & Scenario 2 & Scenario 3 & Scenario 1 & Scenario 2 & Scenario 3 \\
\hline Basic materials & 1.21 & 1.56 & 1.88 & 1.84 & 2.13 & 2.32 \\
Communications & 1.17 & 1.45 & 1.70 & 1.68 & 1.90 & 2.03 \\
Consumer, cyclical & 1.14 & 1.35 & 1.52 & 1.23 & 1.42 & 1.56 \\
Consumer, non-cyclical & 1.15 & 1.41 & 1.64 & 1.37 & 1.59 & 1.78 \\
Energy & 1.05 & 1.13 & 1.19 & 1.01 & 1.02 & 1.06 \\
Financial & 1.29 & 1.78 & 2.24 & 3.17 & 3.22 & 3.23 \\
Industrial & 1.21 & 1.57 & 1.92 & 1.82 & 2.12 & 2.31 \\
Technology & 1.28 & 1.87 & 2.45 & 3.23 & 3.50 & 3.80 \\
Utilities & 1.28 & 1.73 & 2.14 & 2.07 & 2.41 & 2.65 \\
\hline
\end{tabular}

Economic capital requirements calculated using the Basel II IRB risk weight function assuming no maturity correction, correlation of 0.3 , and loss-given-default of 0.4. Source: author's calculations. 
In the baseline risk regimes, the price shocks of 10 percent, 20 percent, and 30 percent cause the median capital requirements to increase on average by 20 percent, 54 percent, and 85 percent respectively in the baseline risk regime, and by 94,114 and 130 percent respectively in the stress regime. Exposures to the energy sector, which is already in a very high risk and stressed regime (see Table 5), do not require a substantial capital increase.

\section{Conclusions}

This paper has introduced the DD-PD mapping, which links the equity-based distance-to-default measure derived from the Black-Scholes-Merton structural corporate risk model to real world probabilities of default derived from the Duan-Sun-Wang market-based forward default probability model using quantile regression. Each of the quantile regression lines in the mapping can be associated with a risk regime.

Building up from a bottom-up perspective, i.e. firm by firm, the DD-PD mapping serves to identify the current risk regime of individual firms, industry groups, and/or industrial sectors. The mapping also enables analysts to perform simple but powerful what-if scenario analysis simulating shocks to the reduced number of parameters that determine the distance-to-default of firms. The shocks can be fitted from qualitative narratives, or as in the case of multiperiod models, from separate quantitative exercises. The what-if analysis can be performed either along the current baseline risk regime the firm is actually experiencing, or under a stressed risk regime. Such analysis could be useful for managing risks in corporate credit portfolios and in regulatory stress tests analysis.

An application to the United States corporate sector illustrates the usefulness of the model. The results of the baseline risk regime analysis indicate that a sustained price correction of 10 percent could cause probabilities of default to rise 30 to 70 percent above their end-December 2020 levels. The most affected firms would be those in the energy, financial, and technology sectors. In a stress analysis, probabilities of default could be one order of magnitude higher in the latter two sectors.

This section closes discussing three other potential uses of the DD-PD mapping not explored in detail here but worth putting forward. The first one is to analyze the effect of changes in the liability structure of a firm on its PD. Once default risk is quantified it could be possible to factor that in the cost of capital of the firm and determine its optimal capital structure (Leland and Toft, 1996; Leland, 2019).

The second one is to examine the impact of monetary policy on the default risk of the firm. This would require assessing first the relationship between equity prices and the risk-free rate. As Figure 2 above illustrates, such relationship does not appear to be stable over time. Once the relationship is established a straightforward application of the DD-PD mapping would yield the results.

The final use is to use the mapping to model potential migration across risk regimes of individual firms and/or corporate sectors in scenarios contemplating either secular or cyclical changes via the values in the exogenous covariates. The PD analysis could then provide guidance for the composition of credit portfolios

and projecting the cost of capital firms could face in long-term scenarios such as those characterizing climate change investment decisions. 


\section{References}

Adrian, T., F. Grinberg, N. Liang, S. Malik. 2018. The term structure of growth-at-risk. IMF WP 18/180.

Baldassari, G., Y. Zhang, R. Tunuguntia. 2017. Macro-scenario model: conditioning credit risk transitions on macro-economic scenarios. S\&P Global Market Intelligence. December.

Bank for International Settlements. 2020. Market rise despite subdued economic recovery. BIS Quarterly Review, September, pp. 1-14.

Basel Committee on Banking Supervision. 2005. An explanatory note on the Basel II IRB risk weight functions. Bank for International Settlements.

Black, F., M. Scholes. 1973. The pricing of options and corporate liabilities. J. of Political Economy 81(3): 637-654.

Bohn, J.R., R.M. Stein. 2009. Active Credit Portfolio Management in Practice. John Wiley and Sons.

Brunnermeier, M.K., M. Oehmke. 2013. Bubbles, financial crises, and systemic risk. Chapter 18 in Constantinides, G., M. Harris, R.M. Stulz (eds.) Handbook of the Economics of Finance, Vol. 2. North Holland, Elsevier.

Chan-Lau, J.A. 2009. Default risk codependence in the global financial system. In Gregoriu, G. (editor) The Banking Crisis Handbook. CRC Press.

Chan-Lau, J.A. 2019. Systemic Risk Assessment and Oversight. Second edition. Risk Books.

Chan-Lau, J.A., Y. Zhao. 2020. Hang in there: stock market reactions to withdrawals of Covid-19 stimulus measures. COVID Economics 60: 57-79.

Credit Research Initiative. 2019a. Bottom-Up Default Analysis (BuDA v3.1.1). Available at https: //d.nuscri.org/static/pdf/BuDA\%20White\%20Paper.pdf

Credit Research Initiative. 2019b. Probability of default. White paper. Available at http://d.nuscri.org/stati c/pdf/Probability\%20of\%20Default\%20White\%20Paper.pdf

Credit Research Initiative. 2020. NUS Credit Research Initiative Technical Report. Available at http: //d.nuscri.org/static/pdf/Technical_report\%202020update2.pdf

Crosbie, P., J.R. Bohn. 2003. Modeling default risk. Moody's KMV. December 18.

Duan, J.-C. 1994. Maximum likelihood estimation using price data of the derivative contract. Mathematical Finance 4(2): 13-32.

Duan, J.-C., A. Fulop. 2013. Multiperiod corporate default prediction with the partially conditioned forward intensity. Working paper. National University of Singapore.

Duan, J.-C., T. Wang. 2012. Measuring distance-to-default for financial and non-financial firms. Global Credit Review 2: 95-108.

Duan, J.-C., W. Miao, J.A. Chan-Lau, CRI staff. 2020. BuDA: A Bottom-Up Default Approach. Available online at https://nuscri.org

Duan, J.-C., J. Sun, T. Wang. 2012. Multiperiod corporate default prediction - a forward intensity approach. J. of Econometrics 170(1): 191-209. 
Duffie, D., K.J. Singleton. 1999. Modeling term structures of defaultable bonds. The Review of Financial Studies 12(4): 687-720.

Gordy, M. 2003. A risk-factor model foundation for ratings-based bank capital rules. J. of Financial Intermediation 12(1): 199-232.

International Monetary Fund. 2016. Western Hemisphere: Managing Transitions and Risks. World Economic and Financial Surveys, Regional Economic Outlook. April.

International Monetary Fund. 2020. Global Financial Stability Report. October.

Koenker, R., G. Bassett. 1978. Regression quantiles. Econometrica 46(1): 33 -50.

Kraemer, N., L. Fernandes, S. Pranshu, N. Richhariya. 2020. Default, transition, and recovery: 2019 annual global corporate default and rating transition study. S\&P Global Ratings. Available at https: //www.spglobal.com/ratings/en/research/articles/200429-default-transition-and-recovery-2019annual-global-corporate-default-and-rating-transition-study- 11444862

Lando, D. 2004. Credit Risk Modeling. Princeton University Press.

Leland, H. 2019. Bond prices, yield spreads, and optimal capital structure with default. risk. Finance 40(3): $45-75$.

Leland, H., K. Toft. 1996. Optimal capital structure, endogenous bankruptcy, and the term structure of credit spreads. J. of Finance 51(3): 987-1019.

Merton, R.C. 1974. On the pricing of corporate debt: the risk structure of interest rates. J. of Finance 29(2): 449-470.

Miyajima, K., J.A. Chan-Lau, W. Miao, J. Shin. 2017. Assessing corporate vulnerabilities in Indonesia: a bottom-up default analysis. Asia-Pacific Financial Markets 24(4): 269-289.

Nazeran, P., D. Dwyer. 2012. Credit risk modeling of public firms: EDF9. Moody's Analytics. June 28.

Shumway, T. 2001. Forecasting bankruptcy more accurately: a simple hazard model. J. of Business 74: $101-124$.

Simons, D., F. Rolwes. 2018. Macroeconomic default modeling and stress testing. International J. of Central Banking 5(3): 177-204.

Tressel, T., X. Dao. 2020. Global corporate stress test: COVID-19 impact and medium term implications. Working paper. International Monetary Fund.

Vassalou, M., Y. Xing. 2004. Default risk in equity returns. J. of Finance Vol. 59(2): 831-868. 